\title{
ANGIO-LEIOMYOMA: AN INTRAMUSCULAR LESION CAUSING SEVERE PAIN IN A CHILD Report of a Case
}

\author{
P. G. Jones, Melbourne, Australia
}

From the Royal Children's Hospital, Melbourne

Episodes of severe pain arising in a poorly localised, impalpable lesion causing bizarre behaviour and gait present difficulties in diagnosis and treatment. The removal of an unusual and almost unique tumour from a child with supposedly hysterical symptoms led to a search of the literature for similar cases, and prompted this report.

\section{CASE REPORT}

The patient, a girl, was healthy until the age of seven years when she was struck by a swing on the outer side of the right thigh a few inches above the knee. Pain was extremely severe although there was no bruising or swelling. The pain subsided within two days, leaving only some local tenderness, but for three years thereafter her gait was abnormal: she walked on the toes of the right foot with the right knee flexed slightly and the right hip medially rotated.

During those three years the same area of the thigh was the site of three similar episodes, all of which followed minor trauma. On each occasion pain was the main feature and out of proportion both to the injury and to the local signs; she was unable to walk for two to five days and hopped on the left leg with the right knee flexed. Between these attacks the skin of the affected area was constantly hyperaesthetic, particularly to warmth and to even the lightest touch. In each of the three acute episodes the same area was thought to have become slightly swollen and the hyperaesthesia worse. Radiographs showed no abnormality.

At the age of ten years a light blow to the thigh precipitated a further episode; five days later she was still unable to walk, but moved around by hopping on the left leg. The last 15 degrees of passive extension of the knee caused severe pain in the affected area, and she held the leg rigid when this extension was attempted. There was a faint bluish blush 10 centimetres in diameter centred on the patella, outlining an area which was faintly warmer than the rest of the thigh. There were also scattered patches of mottled skin, salmon pink in colour, extending over the lower third of the right thigh but not especially over the area of hyperaesthesia. The patient was tearful and terrified of even the gentlest touch-so much so that her reactions could well be described as hysterical.

One week after the fourth episode began the hyperaesthesia was subsiding and an ill-defined, slightly indurated swelling 4 centimetres in diameter was now palpated with certainty, for the first time, in the area of hyperaesthesia.

Operation-Under anaesthesia, and with tourniquet control, an incision was made over the affected area. There was no evident abnormality in the skin or subcutaneous tissue, nor in the underlying ilio-tibial tract. When this fascia was incised, the superficial fibres of vastus lateralis were found slightly oedematous and stained green with altered blood. These fibres were separated and in the deepest part of the vastus lateralis there was a non-encapsulated indurated area containing a few large thick-walled venous channels and nodules of thrombosis, set in bruised oedematous tissue. The abnormal tissue, roughly circular and measuring $5 \times 3$ centimetres and 1 centimetre thick, was removed; its deep surface had to be separated from the periosteum of the lateral condylar ridge of the femur. 
When the patient regained consciousness a broad smile supported her statement that "the feeling" had gone, even though the usual post-operative discomfort was present. She has had no further symptoms of any kind.

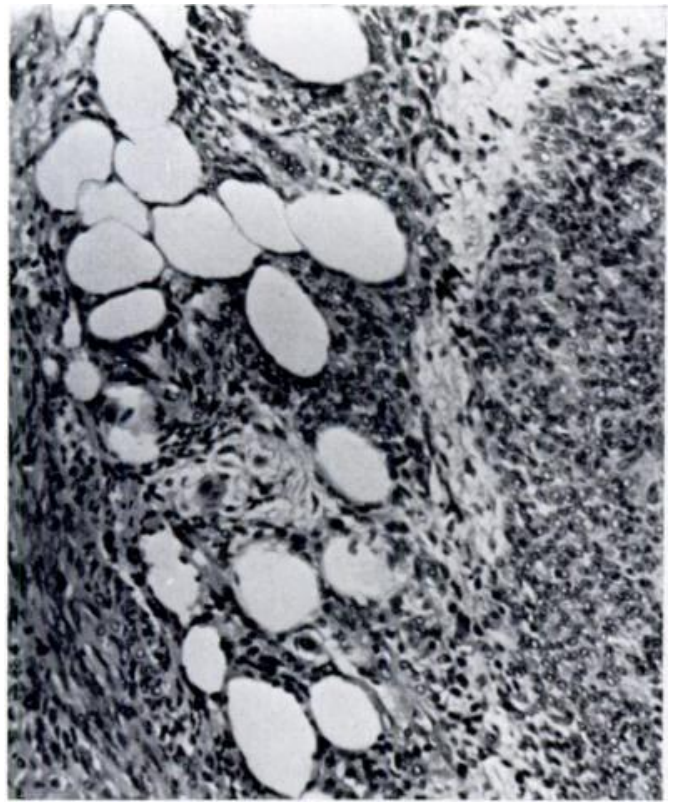

FIG. 1

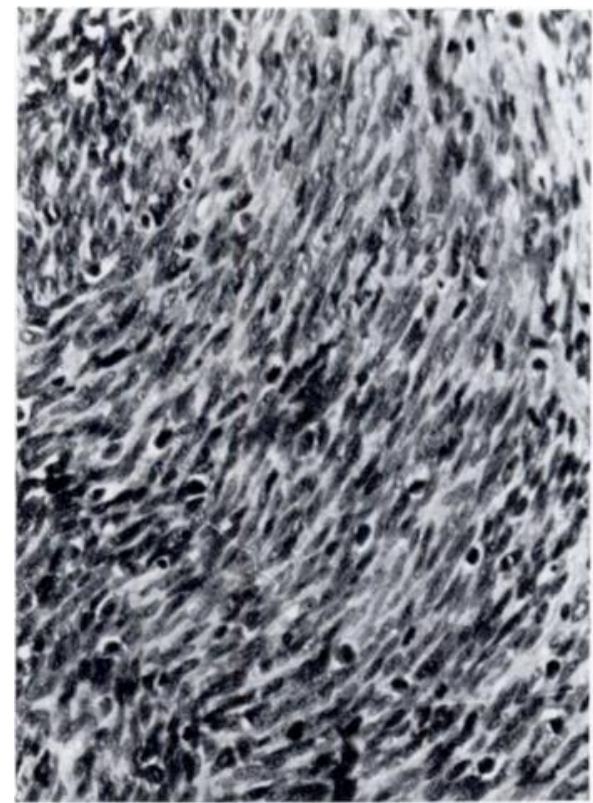

FiG. 2

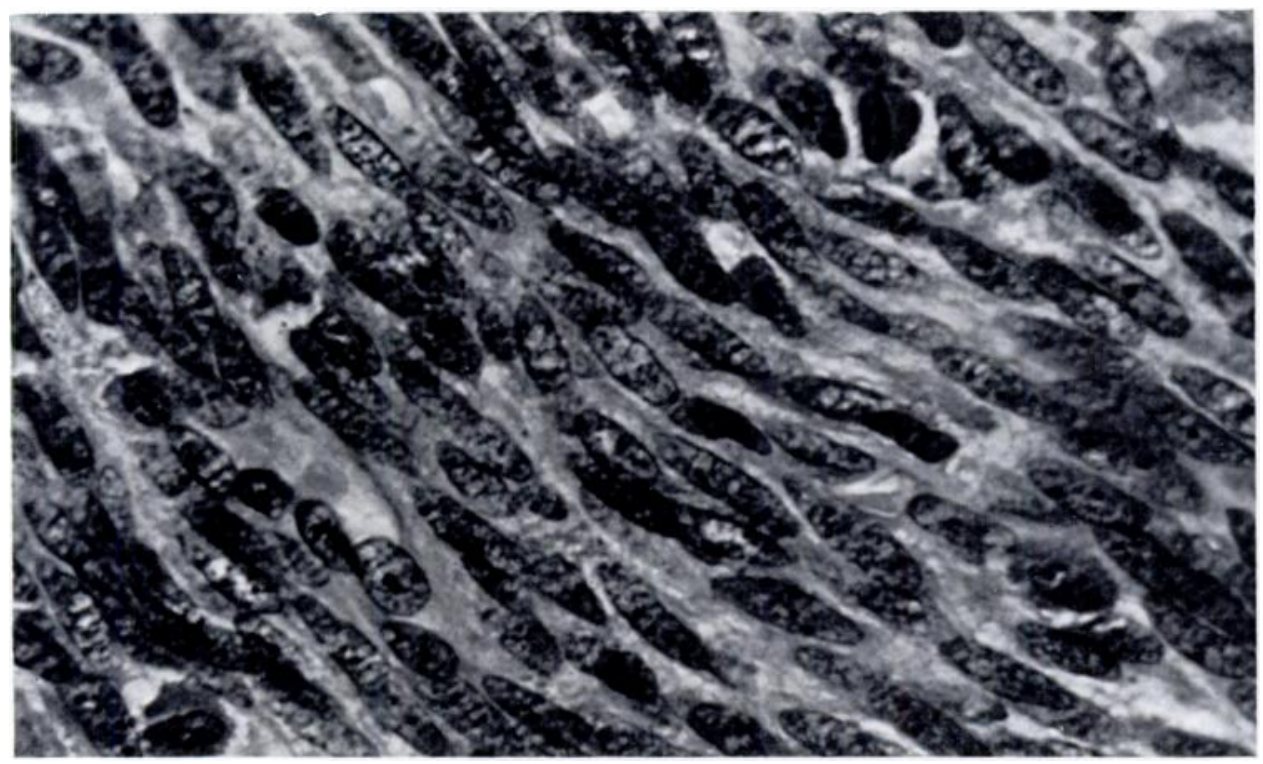

FIG. 3

Leiomyoma showing variations in the pattern of the smooth muscle cells. Figure 1-Muscle cells infiltrating fat. Figure 2-The cells lying parallel in bundles sectioned in the plane of the cells. Figure 3-High power view showing cellular detail.

Histology-The specimen was irregularly lobulated. On microscopic examination, the tissue was composed of several large vascular spaces, some containing organising thrombus, together with an extensive sheet of spindle-shaped cells resembling smooth muscle (Fig. 1). These 
cells were interlaced with, and continuous with, the cells surrounding the vascular spaces. Sections stained for reticulin showed massive deposits of reticulin around the tumour cells. There was no nuclear anaplasia or evidence of mitotic activity, and although there was a suggestion of infiltration into the fat at the margins of the tumour there was no convincing histological evidence of malignancy. The appearance was that of a vascular leiomyoma.

\section{DISCUSSION}

In a patient with episodic focal hyperaesthesia, the diagnosis that most readily comes to mind is glomus tumour, particularly when there are no signs of any abnormality in the area affected.

The clinical features of the glomus tumour were first reported by Barré in 1920, and in the same year the histological characteristics and a mechanism by which the symptoms could be produced were described by Masson (1924). Many of the cases reported are associated with a history of trauma to the site of the lesion: Bailey (1935) noted this in half of sixty-five cases that he collected. The symptoms vary greatly: a few are painless and cause no paraesthesia of any kind. In most cases, however, the pain is searing, sudden in onset and triggered by a touch at or near the site of the "glomangioma" or "angioneuromyoma" (Barré 1920, Masson 1924, Bailey 1935, Mackey and Lendrum 1936). Regional autonomic signs such as alterations in the temperature and colour of the skin, sometimes beyond or unrelated to the site of the lesion, have also been described (Mackey and Lendrum 1936, Lendrum and Mackey 1939).

The patient reported here showed almost all of the classic signs of a glomus tumour, and this was the pre-operative diagnosis. But there were grounds for doubt because of the rarity of the lesion, especially in childhood, and particularly in the leg. The youngest patient reported to have a glomangioma was twelve years old (Lendrum and Mackey 1939), and the majority are in the upper limb-thirty of sixty-four collected by Bailey (1935); twenty of these thirty were subungual, the typical site, as were four of the eleven cases described by Stout (1935).

The histological features of a glomangioma include collections of spindle cells resembling smooth muscle fibres surrounding vascular spaces, nerve fibres and terminals, and the distinctive "glomus cells" which are also arranged around vascular spaces.

The tissue removed from our patient included all these features except the glomus cells and neural tissue, and the histological report led to a search of the literature. The first report of leimyomas in the limbs was by Stout (1937) and concerned fifteen cases, all cutaneous or subcutaneous, all in adults. He also noted that in some of these the clinical features were not unlike those of a glomus tumour and that both types of lesion had a close relationship with blood vessels, but he thought that the sympatheticomimetic reactions of leiomyomas to pharmacological experiments suggested their origin from sweat glands or pilomotor muscle fibres.

Duhig and Ayer (1959) collected sixty-one cases of vascular leiomyoma, all of which were subcutaneous; five were in the thigh, forty-three below the knee, and six on the forearm or hand-a preponderance in the lower limb and the direct opposite of glomangiomas. In their cases pain was not a constant feature, being present in only twenty-seven ( 44 per cent) of the sixty-one cases, and the remainder presented as a small ( 0.5 to 2 centimetres) subcutaneous swelling. In those with pain, it occurred spontaneously in two, in others when bumped or touched, and was described as sharp and knife-like.

Duhig and Ayer considered that vascular leiomyomas constituted a special group with varying histological features as follows: 1) an angioma with much non-striated muscle; 2) a vascular leiomyoma; 3) leiomyoma with many blood vessels; 4) solid leiomyoma. They also suggested that spasm of the blood vessels might cause ischaemia in the associated smooth muscle fibres and that this might explain the peculiar quality of the pain.

The only case in the literature which resembles the one reported here was described by Goodman and Briggs (1965) in a five-year-old girl who had severe pain following a fall, and 
was found to have an encapsulated fusiform leiomyoma measuring $7 \cdot 5 \times 5 \cdot 4 \times 5$ centimetres situated deep in the vastus medialis. Although there are many similarities to our patient, there are also some differences-for instance the mottling of the skin and persisting hyperaesthesia.

In retrospect, the continuous flexion of the knee in our patient may be interpreted as a means of relaxing the ilio-tibial tract, thus preventing pressure on the sensitive lesion in the underlying vastus lateralis. The periodicity of the acute episodes probably reflects chance blows to the site of the lesion, and the ensuing pain lasting several days could have been due to small contusions around, or thrombosis in, the vascular spaces, as seen at operation.

The causalgic type of pain and the chronic hyperaesthesia are more difficult to explain, especially in the absence of any demonstrable neural tissue in the lesion. These symptoms, and the altered colour and temperature of the skin, were probably reflex phenomena, both somatic and autonomic, mediated through the usual spinal arc and referred to the appropriate dermatome (L.3-4).

Finally, there is a moral to this tale: "hysterical" symptoms, however bizarre, may have a rational explanation and a removable organic lesion as the underlying cause.

I am grateful to Mr M. B. Menelaus for the opportunity to see this patient, and we are grateful to Dr Peter Campbell of the Department of Pathology at the Royal Children's Hospital for the diagnosis, the report of the histology and for the photographs subsequently prepared by the Photographic Department.

\section{REFERENCES}

Bailey, O. T. (1935): The Cutaneous Glomus and its Tumors: Glomangiomas. American Journal of Pathology, $11,915$.

BARrÉ, J.- A. (1920): Troubles sympathetiques étendus et violents du membre supérieur par tumeur du doigt. Revue Neurologique, 27, 942.

Duhig, J. T., and Ayer, J. P. (1959): Vascular Leiomyoma: A Study of Sixty-one Cases. Archives of Pathology, $68,424$.

Goodman, A. H., and Briggs, R. C. (1965): Deep Leiomyoma of an Extremity. Journal of Bone and Joint Surgery, 47-A, 529.

Lendrum, A. C., and Mackey, W. A. (1939): Glomangioma: a Form of "Painful Subcutaneous Tubercle". British Medical Journal, 2, 676.

Mackey, W. A., and Lendrum, A. C. (1936): Three Cases of Glomangioma or Angioneuromyoma (Painful Subcutaneous Tubercle). British Journal of Surgery, 24, 208.

Masson, P. (1924): Le Glomus neuromyo-artériel des régions tactiles et ses tumeurs. Lyon chirurgical, 21, 257.

Stout, A. P. (1935): Tumors of Neuromyo-arterial Glomus. American Journal of Cancer, 24, 255.

Stout, A. P. (1937): Solitary Cutaneous and Subcutaneous Leiomyoma. American Journal of Cancer, 29, 435. 